\title{
A passagem do tempo no além: projeção de maturidade no altar de lulia Victorina
}

\author{
Jaqueline Souza Veloso' \\ DOI 10.20396/eha.vil4.3453
}

A presente comunicação tem como objetivo analisar um dos possíveis significados atribuíveis ao altar de lulia Victorina (Figuras 01,02,03,04), que é justamente o que se refere à passagem de tempo. Dessa maneira, outros significados não serão analisados ainda que sua existencia seja discutida, por por exemplo D`Ambra, Hijmans e Berly Rawson².

Para dar curso à análise do altar em questão, abordarei primeiramente dois outros casos onde há projeção de maturidade que nos servirão como um contraponto para comparações.

No altar funerário de Gaius Petronius Virianus (100-110 d.C), morto com 10 anos (Figura 05), o menino é representado com os atributos de um cavaleiro. Mesmo que a aparência de Virianus seja de uma criança, ele está vestido como um membro da ordem equestre ou da cavalaria romana. Ou seja, ele é nitidamente projetado como um cavaleiro. A coroa de louros que traz consigo era utilizada numa procissão anual que acontecia em 15 de julho - transvectio equitum - na qual membros da ordem equestre se posicionavam em frente ao templo de Marte, nos arredores da cidade de Roma.

Nesse caso, é a relação entre a aparencia infantil e atributos apenas realizáveis à idade adulta que permitem ${ }^{3}$ que ele seja considerado um caso de projeção de maturidade, uma vez que nele vemos refletidas as expectativas que eram depositadas sobre o menino quando vivo representadas de maneira visual.

A projeção de maturidade era um recurso que poderia servir como uma forma de lamento fúnebre ao destacar os desejos que pareciam possíveis de serem realizados agora interrompidos pela morte. Entretanto, ainda que amplifique o phatos e o lamento a imagem de projeção servia como um dispositivo para consolar os vivos. Na imagem e na memória que essas imagens suscitariam aquelas crianças atingiriam a maturidade da forma esperada.

Para entender melhor essa questão no pensamento romano referente a representar ou não

\footnotetext{
1 Mestre em Artes pela Universidade do Estado do Rio de Janeiro (UERJ).

2 Respectivamente em: D’AMBRA, E. Beauty for Roman Girls: Portraits and Dolls. In: Girls in Antiquity (Susane Moraw e Anna Kieburg. (Orgs). Munique: Waxmann, 2014, em: HIJMANS, S. The Sun in the Art and Religions of Rome. Holanda: Rijksuniversiteit Groningen, 2009. Outrossim RAWSON, B. Children and Childhood in Roman Italy. Nova York: Oxford University Press, 2005.

3 CARROLL, M. Infancy and Earliest Childhood in the Roman World. Reino Unido: Oxford University Press. p. 247.
} 

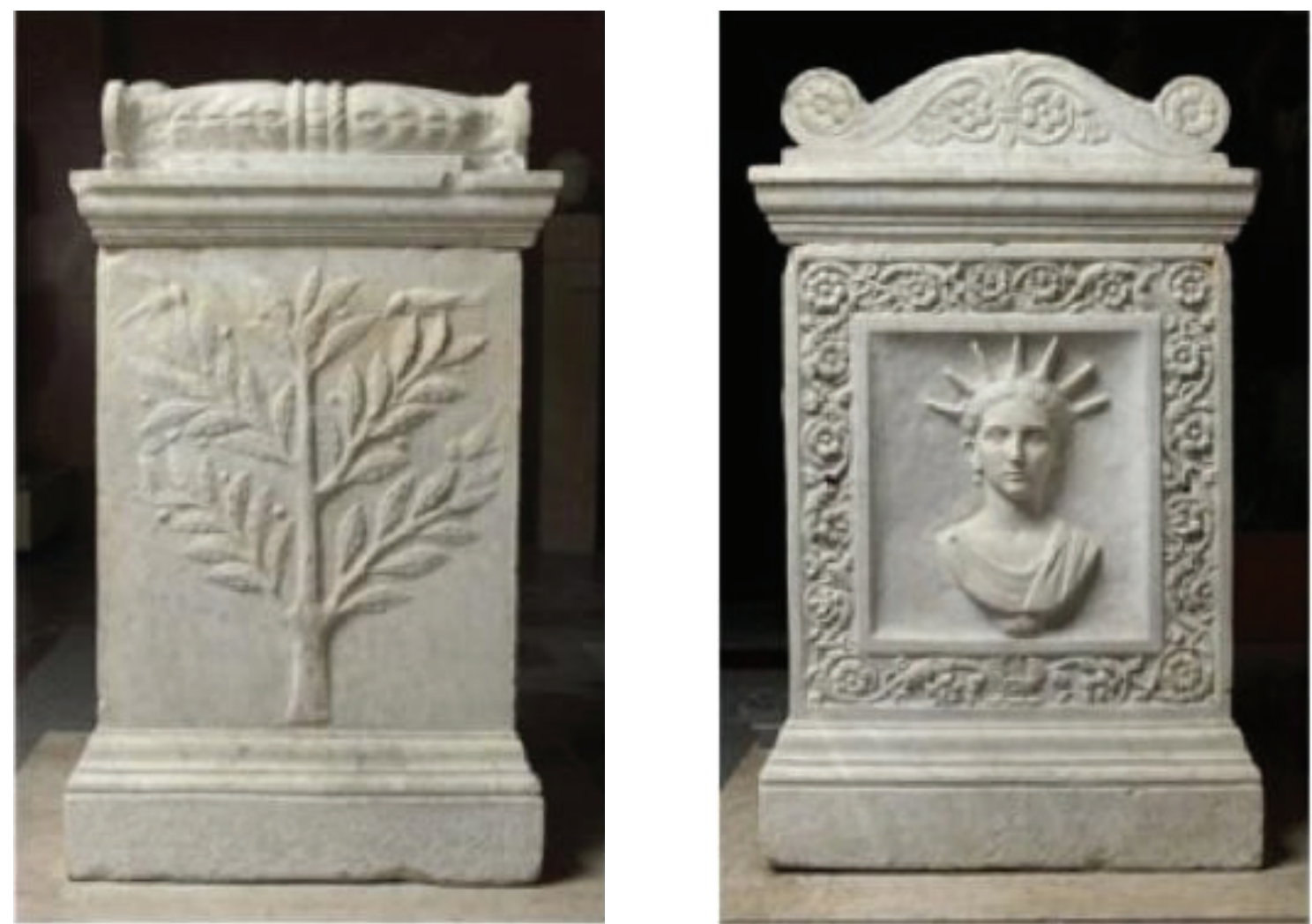

[Figuras 01, 02, 03 e 04] Alfar Funerário de Iulia Victorina. Proveniência: Roma, Jardins de Campana próximo a S. Giovanni em Laterano. Localização Atual: Museu do Louvre. Data: 60-70 D.C. (Kleiner).

Dimensões: 1145x700cm. Inventário: MA1443. Fonte: http://art.rmngp.fr/fr/library/artworks/autel-funeraire-de-julia-victorina-morte-a-10-ans-et-5-mois_marbre_relief-sculpture consultado em 15 de julho de 2019.
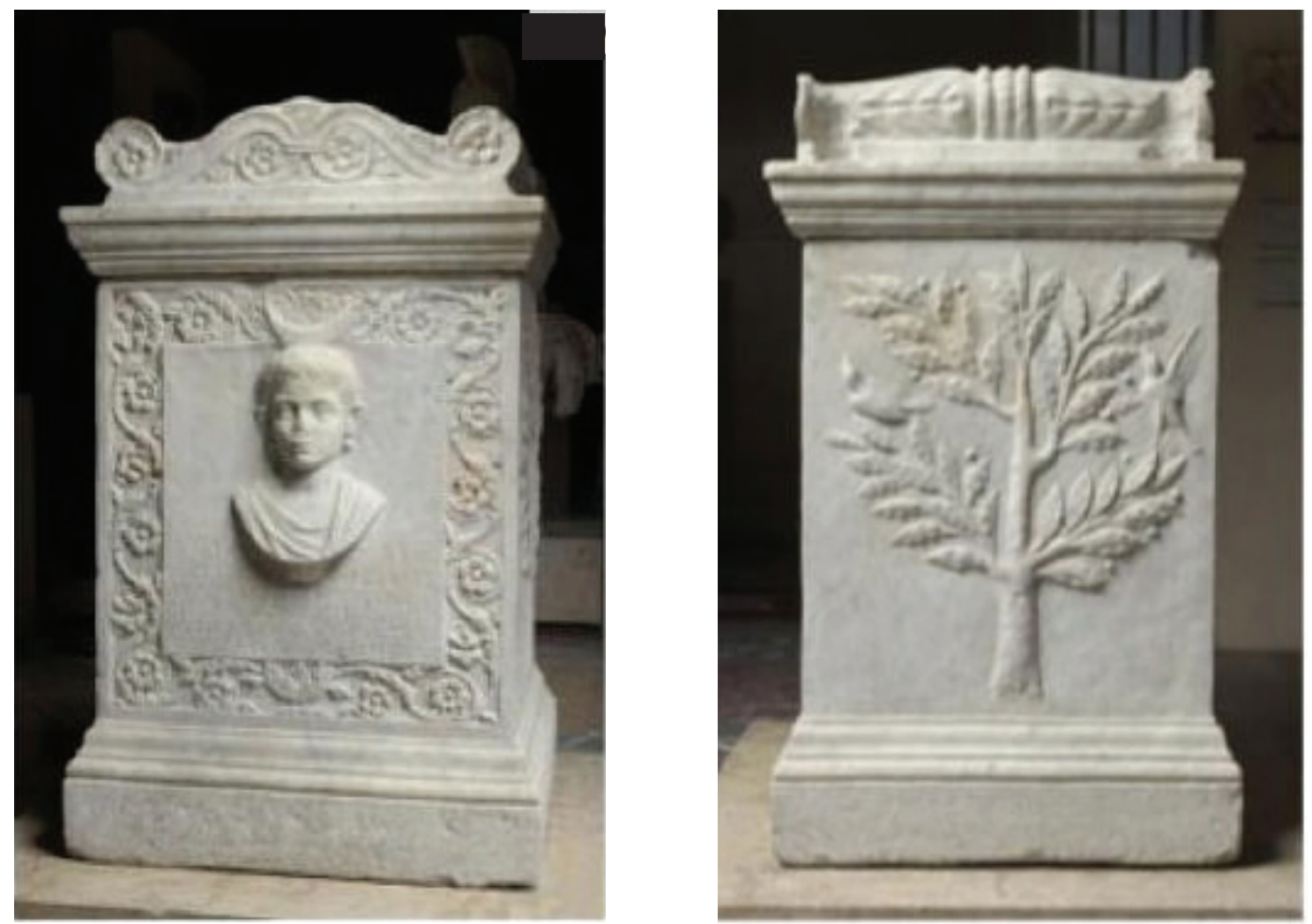


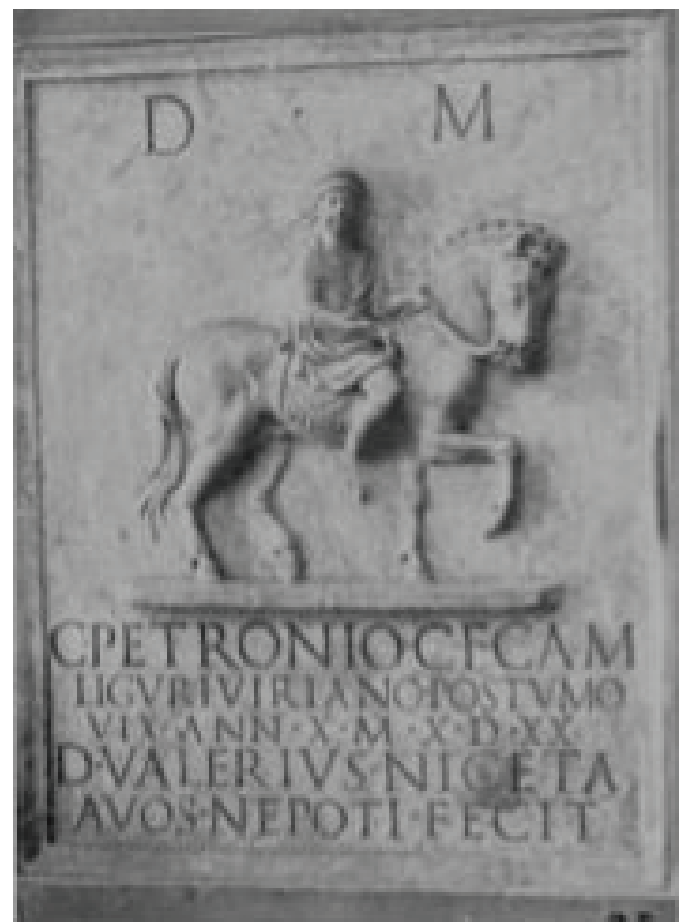

\section{[Figura: 05]}

Altar funerário de Altar de Gaius Petronius Virianus Postumus. Proveniência: Rome, Giustininani Collection. Localização Atual: Roma, Coleção Albani, Museu Capitolino. Data: 100110 D.C.

Dimensões: Altura: 0, 59 m., Largura: $0.285 \mathrm{~m}$. Profundidade: $0,44 \mathrm{~m}$. Inv. 7264. Fonte: Kleiner D. E.E. Roman Imperial Funerary Altars with Portraits. Italia: Giorgio Bretschneider Editore, 1987. Cat. $\mathrm{N}^{0} 63$ PL. XXXVII. I.
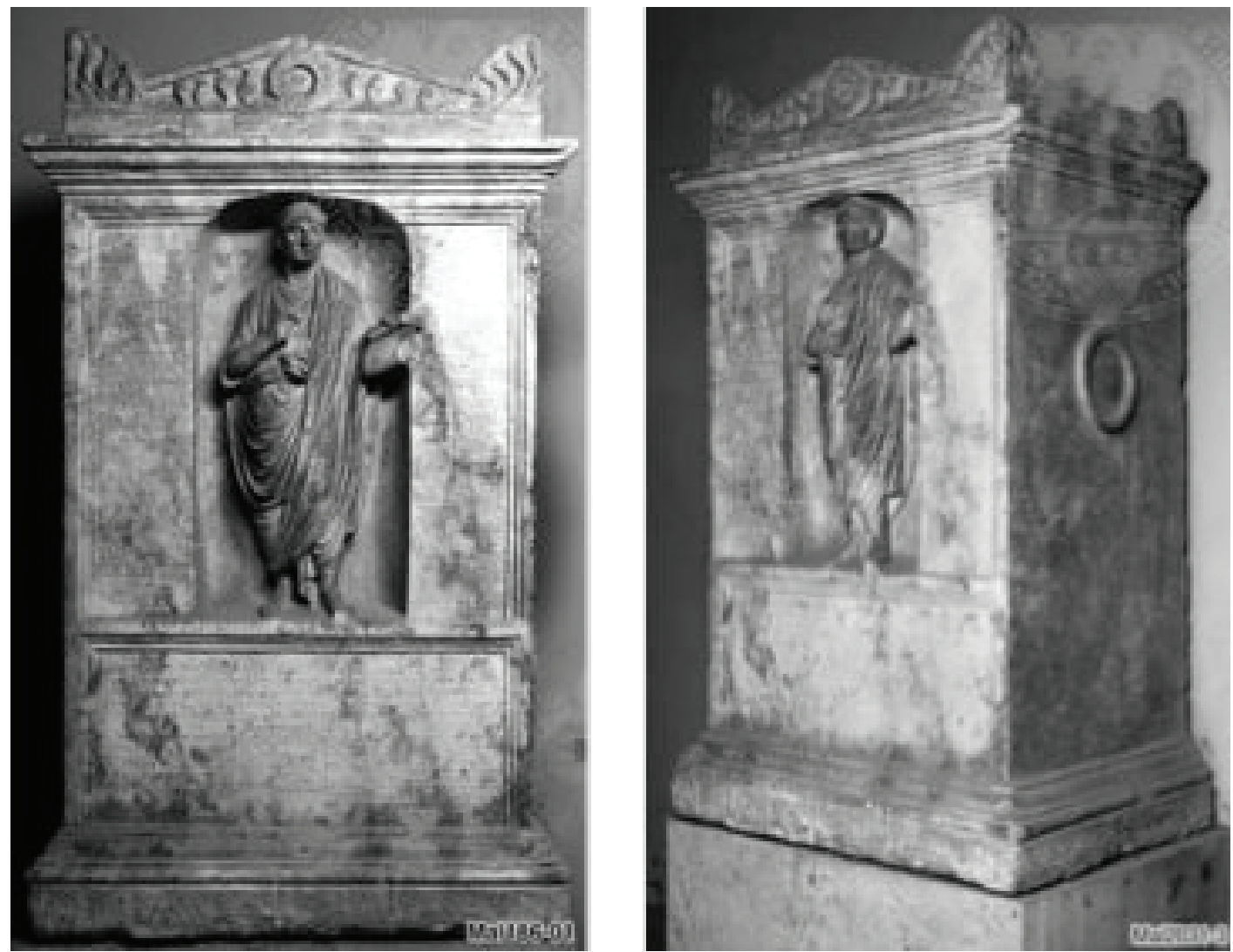

[Figuras 06 e 07] Altar funerário de Q. Sulpicius Maximus. Proveniência: Porta Salaria sob a Torre Oriental, Necrópole 1871. Localização Atual: Museu Capitolino, Sala VI. Data: 94-100 D.C.

Dimensões: Altura: 1,61 m, Largura: 0, 76m, Profundidade: 0,76. Inventário:1102. Fonte:https://arachne.unikoeln.de/ arachne/index.php?view[layout]=objekt_item\&search[constraints][objekt][searchSeriennummer]=39706. Visualizado em: 15 de julho de 2019. 
uma imagem de grande apelo emocional temos a fala de Quintiliano em Insitutio Oratoria ${ }^{4}$ acerca da tragégia pintada por de Timantes na chamada Casa dos Amores Fatais em Pompéia na qual ele diz:

"Tendo exaurido seus poderes de expressão emocional (na pintura) ele não conseguiu retratar o rosto do pai como ele merecia e resolveu o problema ao colocar um véu sobre sua cabeça e deixar o tristeza pelo seu ponto de vista de cada espectador." (Tradução da autora).

$\mathrm{Na}$ análise de Koortbojian ${ }^{5}$ acerca dessa passagem de Quintiliano, em suas palavras: "A expressão de horror (...) ditada por circunstâncias trágicas era mais poderosa sugerida do que retratada (...)". Em outras palavras, a imaginação poderia ser um recurso para amplificar aquilo que não estava representado e, nesse caso, fazendo um sentido oposto, representar poderia ser um recurso para diminuir e inibir pensamentos e imaginações ruins e dolorosas. Dois epitáfios romanos, a título de exemplo, corroboram para essa hipótese. No primeiro deles, lê-se: "Em seu lugar, guardo uma semelhança, como consolo para nós, que o adoramos piedosamente, e muitas guirlandas são oferecidas ${ }^{6}$.

No segundo: "Quando [seus pais] contemplarem suas características, você lhes dará consolo7." O caminho inverso, que suscita a imaginação foi utilizado pelo escritor Luciano ${ }^{8}$ de maneira satírica para intensificar a lamentação de um rapaz, quando reforça que ele era bonito e que deixou os parentes "antes de casar, ter filhos, servir ao exército, trabalhar no campo, envelhecer e nunca mais vai vagar pelas ruas, se apaixonar ou beber em festas". A imagem já concebida nos altares de projeção de maturidade evitava a criação de imagens mentais e, com elas, um maior sofrimento. Essa é a possibilidade que essa análise aponta.

No caso de Sulpicius Maximus (Figuras 06 e 07) a projeção de maturidade se dá com a utilização de os atributos que apontam para uma pessoa mais velha e conjugados a aparência do menino, que morreu aos 11 anos, mas também é envelhecida. Na imagem ele figura como um jovem adulto.

Abaixo do retrato de Maximus, o texto afirma que o altar foi colocado por seus pais: Quintus

\footnotetext{
4 Quint. Inst. Book: 2.13.13: addidisset Menelao, quem summum poterat ars efficere, maerorem, consumptis adfectibus, non reperiens, quo digne modo patris vultum posset exprimere, velavit eius caput et suo cuique animo dedit aestima ndum. Retirado de: QUINTILIAN. The Orator's Education. Book 1-2. Estados Unidos da América: Harvard University Press, 2002. p. 345.

5 KOORTBOJIAN, M. Mimesis or Phantasia? Two Representational Modes in Roman Commemorative Art. Classical Antiquity, Vol. 24 No. 2 , October 2005. p. 288.

6 Effigiem pro te teneo, solacia nostri / quam colimus sancte sertaque multa datur: CIL 6.37965 = CLE 1988. Retirado de: CORDON, A. E. Illustrated Introduction to Latin Epigraphy. Los Angeles: University of California Press, 1983. p. 147.

7 Vultus tuos intuendo solaci(um) prestas: CLE 1607 = CIL 8.19606. Cf. AEp 1982:984 (istic Fidentia dormit / cui pater hunc tumulum / sibi haec solacia fecit). Retirado de: KOORTBOJIAN, M. Mimesis or Phantasia? Two Representational Modes in Roman Commemorative Art. Classical Antiquity, Vol. 24 No. 2, October 2005. p. 293.

8 LUCIAN. On Funerals I. Grã Bretanha: Loeb Classical Library, 1913. p. 13.
} 
Sulpicius Eugramus e Licina lanuaria, e que o menino improvisou um longo poema em grego em um concurso musical que ocorreu em 94 d.C., disputando com cinquenta e dois poetas. A data do festival, o penteado e feições do menino, o comprimento curto da toga, que permite ver seu calçado, todos esses são traços característicos do período trajânico, e sugerem que o altar foi colocado em algum momento entre 94 e 100 d.C 9 .

À esquerda e à direita do nicho do retrato está inscrito o poema que o levou a vitória, cujas últimas linhas estão no pergaminho que ele segura à mão esquerda. O poema fala sobre uma situação mitológica, uma repreensão de Zeus ao deus Hélio.

Sobre o frontispício, acima de Maximus, há uma coroa de flores, elemento comum na arte funerária romana, mas que aqui carrega a ambiguidade de também representar uma coroa de vitória. As vitórias nos concursos eram frequentemente usadas na arte romana como alegorias para a vitória sobre a morte ${ }^{10}$.

Há dois epigramas gregos que elogiam Maximus abaixo da inscrição latina. Segundo eles, o que causou a morte do menino foi estudar demais. Assim, funcionam como uma espécie de elogio à sua educação, em consonância com os elementos citados até aqui. Por outro lado também nos mostram o quão alegóricos os monumentos funerários romanos poderiam ser, no sentido de ficcionalizar realidades.

O nicho principal contém um retrato de corpo inteiro de Quintus Sulpicius Maximus, falecido, como diz o epitáfio, com onze anos, 5 meses e 12 dias. Entretanto, ele, no retrato, parece estar no início da fase adulta.

O altar de Maximus é essencialmente prospectivo: ele não diz respeito ao passado, porque toda a escrita e imagem corroboram para um vir a ser interrompido pela morte. $E$, nesse caso, não há nenhum elemento que nos aponte que esse vir a ser poderia ser de fato conquistado, por exemplo, numa existência após a morte: não há nenhuma menção a uma temporalidade possível de ser percorrida. A imagem principal unifica todas as pretensões de futuro e, na epígrafe fúnebre, já nos demonstram que a morte impediu o porvir brilhante de Maximus de se concretizar.

No caso de lulia Victorina, erigido no século I d.C e dedicado a uma menina morta com 10 anos e 4 meses, entretanto, a conjunção das duas imagens cria uma espécie de narrativa e os elementos astrais sobre sua cabeça infundem a idéia de temporalidade. O sol e a lua são referenciais para o dia e a noite, para a contagem das estações e dos anos. Além disso o próprio monumento tem

9 KLEINER, D. Roman Imperial Funerary Altars with Portraits. Italia : Giorgio Bretschneider Editore, 1987. p. 165.

10 Op. cit. 
uma configuração que nos obriga a percorrer um caminho durante um certo tempo para observar os dois retratos.

Os duas imagens parecem demonstrar, como no exemplo de Virinanus e Maximus, as esperanças dos pais em vê-la crescer. Se entendermos que trata-se de um caso de projeção de maturidade então as duas faces representam lulia Victorina em momentos distintos de existência. Entretanto, diferentemente dos casos de Virianus e Maximus, cujas imagens que representam maturidade funcionam de forma a consolar suas famílias, a imagem de lulia Victorina mais velha perde o sentido de consolo uma vez que é contraposta com sua imagem à época da morte. Se pensarmos que a imaginação de um futuro brilhante era uma forma de amenizar ou apontar a dor de sua família não faz sentido que essa imagem seja contraposta a uma dela mais jovem a não ser se for com a intenção de demonstrar que a infância seria um ponto de partida para a fase posterior, de maturidade.

Assim, há a sugestão da crença que ela poderia envelhecer de fato por causa da comparação entre as duas imagens e de sua associação a elementos astrais que poderiam ter um sentido de sobrevivência cósmica. Dessa forma, o seu envelhecimento seria apenas possível se ela continuasse existindo após a morte e se nessa existência houvesse temporalidade e amadurecimento físico. $\mathrm{O}$ sol e a lua, que demarcam a passagem dos dias e também uma certa espacialidade por conta do seu trajeto no firmamento poderiam apontar a distância entre a existência mortal, na qual ela faleceu ainda criança e uma outra que é relacionada de maneira engrandecedora ao sol, o astro com o maior brilho.

Portanto, nesse caso, a projeção de maturidade não atua de forma a lamentar um futuro briIhante interrompido pela morte, mas de forma a apontar a possibilidade de que lulia continuaria existindo.

Assim, dentre as diversas possibilidades de interpretação para o altar de lulia Victorina, a que escolhi trabalhar nessa comunicação é a de que os signos astrais conjugados aos dois retratos apontam para um sentido de apoteose astral e, com ele, para um possível destino após a morte. Cícero em em o sonho de Cipião deixa entrever o que seria essa apoteose astral post mortem:

"Abaixo dela (a Lua) tudo é mortal (...) Acima da Lua tudo é eterno. A Terra, (...), é nossa esfera. (...)"11. "(...) se aos beneméritos da pátria abre-se o caminho que conduz ao céu esforçar-me ei na esperança de conseguir tão alta recompense."12

11 CÍCERO. A Velhice Saudável/ O Sonho de Cipião. Brasil: Escala, 2006. P. 95.

12 Ibid., p. 105. 


\section{Referências Bibliográficas}

CíCERO. A Velhice Saudável/ O Sonho de Cipião. Brasil: Escala, 2006.

GORDON, A. E. Illustrated Introduction to Latin Epigraphy. Los Angeles: University of California Press, 1983. p. 147. HUSKINSON, J. Children's Sarcophagi-Their decorations and it's social significance. Inglaterra: Oxford University Press, 1996.

KLEINER, D. Roman Imperial Funerary Altars with Portraits. Italia : Giorgio Bretschneider Editore, 1987.

KOORTBOJIAN, M. Mimesis or Phantasia? Two Representational Modes in Roman Commemorative Art. Classical Antiquity, Vol. 24 No. 2, October 2005.

LUCIAN. On Funerals I. Grã Bretanha: Loeb Classical Library, 1913.

QUINTILIAN. The Orator's Education. Book 1-2. Estados Unidos da América: Harvard University Press, 2002. 